\title{
Intergenerational communication on sexuality and HIV/AIDS: Exploring feasibility of building effective youth-adult partnerships to reduce young people's HIV vulnerabilities
}

Vaishali Sharma Mahendra

Sarat Chandra Pradhan

Saraswati Swain

Aradhana Nanda

Sanjit Patnayak

See next page for additional authors

Follow this and additional works at: https://knowledgecommons.popcouncil.org/departments_sbsr-hiv

Part of the Demography, Population, and Ecology Commons, Family, Life Course, and Society

Commons, International Public Health Commons, and the Medicine and Health Commons

How does access to this work benefit you? Let us know!

\section{Recommended Citation}

Mahendra, Vaishali Sharma, Sarat Chandra Pradhan, Saraswati Swain, Aradhana Nanda, Sanjit Patnayak, Sucheta Panda, and Rajendra Prasad. 2007. "Intergenerational communication on sexuality and HIV/AIDS: Exploring feasibility of building effective youth-adult partnerships to reduce young people's HIV vulnerabilities," Research update. New Delhi: Population Council. 


\section{Authors}

Vaishali Sharma Mahendra, Sarat Chandra Pradhan, Saraswati Swain, Aradhana Nanda, Sanjit Patnayak, Sucheta Panda, and Rajendra Prasad 

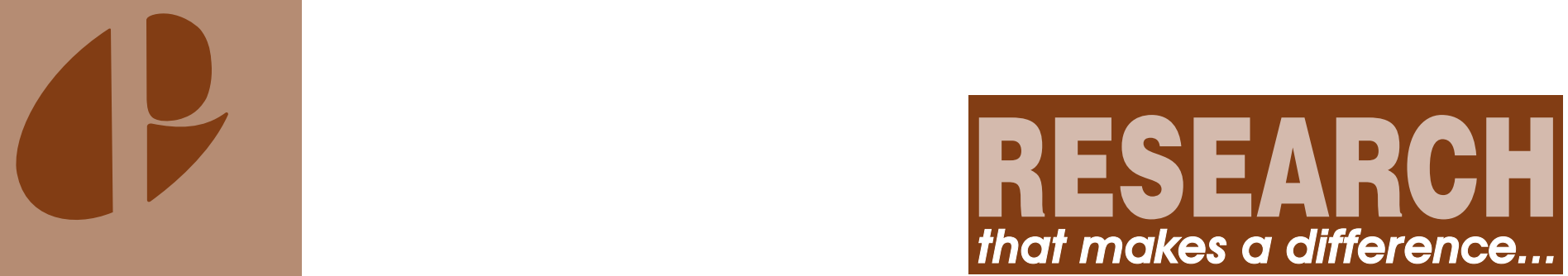

\section{INTERGENERATIONAL COMMUNICATION ON SEXUALITY AND HIV/AIDS: Exploring feasibility of building effective youth- adult partnerships to reduce HIV vulnerabilities of the young}

\section{Background}

In India, over one-third of all reported AIDS cases occur among young people in the age group of 15 to 24 years. ${ }^{1}$ At the same time, they are also our greatest hope for changing the course of the AIDS epidemic. To do so, young people need to have the competencies to navigate daily life situations and engage in productive activities. It is the relationships youth form with both adults and peers that are the source of emotional support, guidance and instrumental help that are critical to the development of their competencies. ${ }^{2}$ The peer-based approach has been established as integral to sexual health and HIV prevention programmes for youth. However, in some settings, programme and policy directions have been hampered by adult beliefs of what young people should be permitted to know. Some recent projects show that working on changing the norms and beliefs of adults in the community facilitates work with youth. However, programme strategies remained 'ad-hoc' possibly because of a lack of clear and agreed upon set of conditions to suggest the need for as well as inform the design and implement an intergenerational approach. The proposed research aimed to address this gap by documenting existing patterns of and barriers to intergenerational communication on sexuality and HIV/AIDS as well as determine the felt need for it by both parents and young people. It will also provide information for designing interventions that promote effective youth-adult partnerships to address HIV risk.

\section{Study Methodology}

\section{Study sites}

The study was undertaken in three distinct settings in Orissa. Three tribal villages in Koraput, two rural villages in Kalahandi and two large urban slums in Cuttack were selected as the study sites based on the NGO-supported HIV prevention activities undertaken in these sites. Also, the three districts were selected to provide an understanding of different populations and cultural settings for the study. The study was implemented in each of the site with a local NGO partner SOVA in Koraput, FARR in Kalahandi and NIAHRD in Cuttack.

\begin{abstract}
Study design
Researchers conducted a cross-sectional study from August 2006 to January 2007 using qualitative and quantitative research methods. A total of 18 group discussions with male youth, female youth and parents were conducted in each site to introduce the study rationale and processes, seek consent from the community and understand existing community patterns of intergenerational communication. In addition, interviews were held with 17 key informants from the three sites, such as village leaders, teachers etc. to explore their perspectives on need for and barriers to intergenerational communication. These discussions were followed by in-depth interviews with 36 male and female youth aged 15-24 years and with one parent (total 36 parents) identified by each youth as the current or preferred source of intergenerational communication. This was followed by a survey of 300 male and female youth aged 15-19 years from all three sites who were selected randomly after researchers had prepared a household listing of young people in the selected villages.
\end{abstract}

Study participants were assessed on their sexual and reproductive health and HIV/AIDS-related knowledge and attitudes, sexual behavior and practices, self-perception of HIV risk, current and preferred sources of information on gender, sexuality and HIV/AIDS in the family and community and suggestions for overcoming barriers to intergenerational communication.

\begin{abstract}
Socio-demographic profile of female and male youth in Koraput, Kalahandi and Cuttack

The median age of the surveyed unmarried male and female youth was 17 years (age range 15-19 years). Of all youth interviewed, over half had dropped out of school, one-fourth was currently studying and one-fifth had never gone to school. Fifty percent of the male and female youth reported being employed with the large majority working as daily wage labour either in construction or in agricultural fields.
\end{abstract}




\section{Key findings}

A considerable proportion of young people were involved in 'casual' or 'time-pass' relationships with youth of the opposite sex for 'having fun', 'physical intimacy such as hugging, kissing', and 'roaming around'. The young men also mentioned 'having sex' as one of the reasons and reported having more than one casual relationship at a time. Young people also talked about 'romantic relationships' that were based on 'emotional attachment' and 'intent to marry'. Over half of the youth ( 40 percent of females and 67 percent males) mentioned they had a romantic relationship with a member of the opposite sex. Two young men mentioned they had a romantic relationship with young men in their community.

One-third of the youth reported they have ever had a sexual relationship, the large majority being young males. The median age at first sex reported by the young males and females is 15.45 years (age range 12-19 years). While young women reported they ever had sex with only one partner, the mean number of sexual partners reported by young men was double (ranged from 1-6 partners). Condom use during last sex in six months was reported by only 60 percent of the young people with more females reporting condom use as compared to males.

While young people reported high levels of awareness about routes of HIV transmission and methods of prevention they also harboured misconceptions and stigmatizing attitudes towards HIV-positive people and those considered at risk. Moreover, when asked if they perceived young people like themselves at risk of HIV infection, the large majority said 'yes'. The reasons mentioned for this perception was that 'young people are keen on experimenting with sex', 'do not have access to services to protect them' and 'are hesitant to discuss their concerns with family at home'.

When youth were asked if they communicate with their parents their health-related concerns, onefourth mentioned discussing their physiological bodily changes with their parents. However, this proportion decreased significantly when it came to discussing HIV transmission, sexual health problems, and sex and sexuality. Most often young people hesitated to discuss these issues with their parents owing to feelings of shyness and embarrassment as well as fear of being beaten or being accused and humiliated by them for having sexual relationships. At the same time, over half of the young people mentioned that parents should communicate with their children on puberty changes, sexual health problems, HIV/AIDS, violence, substance use followed by few who mentioned sex and sexuality and family planning. They felt that parents have their child's best interest at heart and will be able to guide and advise them accordingly.

When asked about preferred source of communication on sexuality and HIV/AIDS, parents were listed closely behind peers. On issues relating to violence, substance use and gender roles, parents were clearly listed as the first choice of the young people. Most youth felt that as parents are 'concerned about my well-being' and will give the 'best advice' thus it is important to promote communication between them. These sentiments were also echoed and supported by parents of the young people. However, the parents also mentioned that the lack of appropriate information, poor skills to provide the information and perception of social taboo were barriers in facilitating communication between parents and their children. To overcome these, both youth and parents suggested that NGOs should organize community meetings for both parents and young people on health problems of youth and encourage them to discuss with each other. Participatory educational sessions on gender, sexuality and HIV/AIDS should be conducted with parents also. Some even mentioned that less sensitive sessions on gender roles, HIV transmission, general health problems, violence and substance use should be conducted jointly with parents and young people (separate groups of male and female youth) while sessions on sexual and reproductive health, sexuality etc. Should be conducted separately. Street plays, theatre and other folk media can also be used to promote the importance of intergenerational communication.

\section{Program implications and recommendations}

The exploratory study suggests that both male and female youth in the low-HIV prevalence state of Orissa are vulnerable to HIV and SRH problems owing to lack of accurate and appropriate information, unsafe sexual practices and poor skills and knowledge of services to protect themselves. At the same time, the young consider that involvement of parents is essential to create a supportive environment in the home that can facilitate required behavior change practices. However, cultural sensitivities need to be considered prior to designing programs for both youth and adults. This is possible by adopting a broader approach to HIV prevention by addressing gender dimensions of vulnerability and risk, sexual and reproductive health needs and care for the young, attitudes towards sex, sexuality and HIV/AIDS and, the link between violence and substance use with risk and vulnerability. Involving parents should thus be seen as a key strategy to supplement peer approach and reach a wider population of youth to reduce their risk to HIV and SRH problems.
Vaishali Sharma Mahendra Population Council 142 Golf Links (First Floor)

New Delhi 110003

Tel: 91- 11-41743410/11

Fax: 91- 11- 41743412

Email: info-india@popcouncil.org

\section{www.popcouncil.org}

\section{Contributors}

Vaishali Sharma Mahendra, Sarat C. Pradhan, Saraswati Swain, Aradhana Nanda, Sanjit Patnayak, Sucheta Panda and Rajendra Prasad

\section{Donor}

Department for International Development, UK 